\title{
EVALUACIÓN DE LA CALIDAD MICROBIOLÓGICA DE PRODUCTOS NATURALES PROCESADOS DE USO MEDICINAL COMERCIALIZADOS EN QUITO, ECUADOR
}

\author{
Diana Carrasco (1),a, Raquel Espinoza (1) 1,a, Gabriela Alejandro (1),a, \\ Jonathan Martínez (1) 1,a,Javier Santamaría-Aguirre (1) ${ }^{1,2}$, Fernanda Zúñiga (i] ${ }^{1, c}$, \\ Pablo Endara $\circledast^{3, d}$, Rommy Terán (1) 1,e \\ 1 Facultad de Ciencias Quimicas, Universidad Central del Ecuador, Quito, Ecuador. \\ 2 Instituto de Investigacion en Salud Publica y Zoonosis, CIZ, Universidad Central del Ecuador, Quito, Ecuador. \\ ${ }^{3}$ Colegio de Ciencias de la Salud, Escuela de Medicina, Universidad San Francisco de Quito, Quito, Ecuador. \\ Bioquímica/o farmacéutica/o; ${ }^{\text {b }}$ Magíster en Tecnología y Control de Medicamentos; \\ Bioquímica clínica; ${ }^{\mathrm{d}}$ máster en Microbiología y en Epidemiología; ${ }^{\mathrm{e}}$ máster en Microbiología y en Inmunología
}

\section{RESUMEN}

Objetivos: Determinar la calidad microbiológica de una muestra de productos naturales procesados de uso medicinal de libre comercio en Quito, Ecuador. Materiales y métodos: 83 productos se sometieron a recuentos de microorganismos aerobios, mohos y levaduras por técnicas convencionales estandarizadas, de acuerdo a la Farmacopea de los Estados Unidos (USP, por sus siglas en inglés). Se identificaron los microorganismos presentes y se determinó su sensibilidad antimicrobiana usando el método de difusión en agar. Resultados: El 17,0\% de los jarabes, el 27,0\% de los productos tópicos y el 43,0\% de los sólidos orales excedieron los límites especificados para el recuento total de microorganismos aerobios, mientras que el 33,0\% de los jarabes, el 7,0\% de los productos tópicos y el 36,0\% de los sólidos orales excedieron el límite para mohos y levaduras. Los productos de uso ocular no pasaron la prueba de esterilidad. El género bacteriano más frecuentemente aislado fue Bacillus, seguido por Escherichia coli, Klebsiella y Enterobacter. Salmonella ni Staphylococcus aureus se encontraron en ningún producto, pero microorganismos potencialmente patógenos como Pseudomonas se aislaron en el 40,0\% de los colirios. Enterobacter y Escherichia coli mostraron resistencia a múltiples compuestos y Pseudomonas no fue resistente a ningún antibiótico. Conclusiones: La calidad microbiológica de los productos examinados no fue adecuada. Se aislaron microorganismos potencialmente patógenos y resistentes a antibióticos. Estos productos podrían no ser aptos para su distribución y consumo, aun cuando muchos de ellos cuenten con registro sanitario. El control y regulación por los entes responsables es indispensable.

Palabras clave: Preparaciones de Plantas; Bacterias; Hongos; Farmacorresistencia Microbiana (fuente: DeCS BIREME).

\section{EVALUATION OF THE MICROBIOLOGICAL QUALITY OF NATURAL PROCESSED PRODUCTS FOR MEDICINAL USE MARKETED IN QUITO, ECUADOR}

Citar como: Carrasco D, Espinoza R, Alejandro G, Martínez J, SantamaríaAguirre J, Zúñiga F, et al. Evaluación de la calidad microbiológica de productos naturales procesados de uso medicinal comercializados en Quito, Ecuador. Rev Peru Med Exp Salud Publica. 2020;37(3):431-7. doi: https://doi. org/10.17843/rpmesp.2020.373.4889.

Correspondencia: Rommy Terán, riteran@uce.edu.ec

Recibido: $18 / 10 / 2019$ Aprobado: $17 / 06 / 2020$

En línea: $21 / 08 / 2020$

\begin{abstract}
Objectives: To determine the microbiological quality of samples from processed natural products used for medicinal purposes and marketed in Quito, Ecuador. Materials and methods: Aerobic microorganisms, molds and yeasts were counted by conventional standardized techniques, according to the United States Pharmacopoeia (USP), in samples from 83 products. The microorganisms found were identified and their antimicrobial sensitivity was determined using the agar diffusion method. Results: The total aerobic microorganism count exceeded the specified limits in $17.0 \%$ of syrups, $27.0 \%$ of topical products and $43.0 \%$ of oral solids; the molds and yeasts count exceeded the limit in $33.0 \%$ of syrups, $7.0 \%$ of topical products and $36.0 \%$ of oral solids. Products for eye use did not pass the sterility test. The most frequently isolated bacterial genus was Bacillus, followed by Escherichia coli, Klebsiella and Enterobacter. Salmonella and Staphylococcus aureus were not found in any product, but potentially pathogenic microorganisms such as Pseudomonas were isolated in $40.0 \%$ of the eye drops. Enterobacter and Escherichia coli showed resistance to multiple compounds and Pseudomonas was not resistant to any antibiotic. Conclusions: The microbiological quality of the products examined was not adequate. Potentially pathogenic and antibiotic resistant microorganisms were isolated from the samples. These products may not be suitable for distribution and consumption, even though many of them have sanitary registration. Control and regulation by the corresponding authorities is essential.
\end{abstract}

Keywords: Herbal Products; Bacteria; Fungi; Microbial Drug Resistance (source: MeSH NLM). 


\section{INTRODUCCIÓN}

Los productos naturales procesados comprenden una variedad de preparaciones a base de plantas que se adquieren sin prescripción médica y que pueden ser considerados como alimentos, suplementos alimenticios, cosméticos y productos herbales de uso medicinal ${ }^{(1)}$. La población acude a su uso por el costo accesible y por la creencia de que tienen menos efectos secundarios que los productos sintéticos. Su uso es cada vez más frecuente, no solamente en países en desarrollo sino también en los industrializados, sin embargo, podrían no ser seguros en el caso de estar contaminados con microorganismos o sus toxinas ${ }^{(2)}$.

Estudios han reportado la contaminación de estos productos con microorganismos potencialmente patógenos, como Salmonella y Staphylococcus aureus ${ }^{(3,4)}$ y otros han mostrado la presencia de bacterias de origen intestinal y ambiental, sugiriendo un escaso control microbiológico en su elaboración y una aplicación inadecuada de buenas prácticas de manufactura (BPM). Es así que los usuarios podrían exponerse a una variedad de microorganismos, muchos de ellos causantes de enfermedades. Algunos de estos productos pueden estar contaminados con bacterias resistentes a antibióticos, como la Staphylococcus aureus resistente a la meticilina ${ }^{(5)}$, lo cual supone su potencial participación en la diseminación de microorganismos farmacorresistentes en la comunidad.

La fabricación y venta de productos naturales procesados de uso medicinal, debería controlarse desde etapas tempranas y a lo largo de todo su ciclo de vida, para garantizar su calidad y seguridad. En el presente contexto, debe entenderse que la calidad farmacéutica es la base que permite a los pacientes y consumidores tener confianza en la seguridad y efectividad de los medicamentos ${ }^{(6)}$; de hecho, la calidad es la base de la eficacia y seguridad reproducibles de los productos naturales, lo que implica la ausencia de contaminantes y residuos que pueden causar daño a los consumidores ${ }^{(7)}$.

En el Ecuador, la autoridad sanitaria ha establecido que un producto natural procesado de uso medicinal es aquel producto medicinal terminado y etiquetado, cuyos ingredientes activos están formados por cualquier parte de los recursos naturales de uso medicinal o sus combinaciones como droga cruda, extracto estandarizado o en una forma farmacéutica reconocida, que se utiliza con fines terapéuticos ${ }^{(8)}$. La venta y el control posregistro están regulados por la Agencia Nacional de Regulación, Control y Vigilancia Sanitaria, ARCSA; sin embargo, en las tiendas naturistas se expenden productos de fabricación local e importados sin la debida certificación ni permisos correspondientes. Además, las empresas nacionales donde se fabrican y comercializan productos naturales han logrado dilatar la obligatoriedad en el cumplimiento de BPM y tienen todavía plazo hasta el 2021 para su implementación ${ }^{(9)}$, mientras

\section{MENSAJES CLAVE}

Motivación para realizar el estudio: En el Ecuador, los estudios sobre la calidad microbiológica de los productos naturales procesados de uso medicinal y de venta libre son escasos y no se ha reportado si tienen microorganismos patógenos y farmacorresistentes.

Principales hallazgos: Porcentajes considerables de los productos analizados no son seguros desde el punto de vista microbiológico y superan los criterios para microorganismos aerobios y para mohos y levaduras. Enterobacter y Escherichia coli aisladas de compuestos sólidos mostraron ser resistentes a múltiples antibióticos.

Implicancias: Se necesitan medidas de control en la fabricación y venta de productos naturales procesados de uso medicinal y la implementación de buenas prácticas de manufactura.

tanto en el país, estos productos siguen siendo comercializados y consumidos.

Debido a que los datos sobre la calidad microbiológica de productos que se venden sin restricción en mercados y tiendas naturistas de la capital de Ecuador son escasos. Este estudio pretende determinar la calidad microbiológica de una muestra de productos naturales: jarabes, cremas, soluciones, colirios, cápsulas y comprimidos; cuantificar la carga microbiana; identificar los microorganismos presentes; $y$ determinar la sensibilidad de estos a los antibióticos.

\section{MATERIALES Y MÉTODOS}

\section{Diseño y muestra}

Un estudio observacional, descriptivo, transversal fue realizado en tres sectores (norte, centro y sur) de la ciudad de Quito. De forma no aleatoria y por conveniencia, se seleccionaron 10 centros naturistas en zonas representativas y de alto comercio. En cada uno se adquirió los productos a disponibilidad del stock del centro naturista, en total se colectaron 83 productos de fabricación local o del extranjero: 24 jarabes, 15 productos de uso tópico (cremas y soluciones), 30 colirios (soluciones) y 14 sólidos orales (comprimidos y cápsulas). El periodo de ejecución del estudio fue de abril del 2018 a julio del 2019.

Se documentó la información de las etiquetas de los productos, como composición, registro sanitario y fechas de elaboración y caducidad, y también si incluían prospecto. Los productos fueron transportados en fundas plásticas selladas al laboratorio de Microbiología General y Farmacéutica de la Facultad de Ciencias Químicas de la Universidad Central del Ecuador y se procesaron en un máximo de cuatro horas después de haber sido adquiridos. 


\section{Verificación de los métodos de recuento}

Para demostrar la validez de los métodos de recuento, se agregó a los productos diluidos y a un control (sin incluir la muestra), un volumen suficiente de suspensión microbiana para obtener un inóculo de no más de 100 unidades formadoras de colonias ( $\mathrm{ufc}$ ) de cepas estandarizadas de microorganismos según lo especificado en la Farmacopea de los Estados Unidos (USP, por sus siglas en inglés) ${ }^{(10)}$. El método se consideró apto si el número de ufc recuperadas de los productos no difería en un factor mayor a 2 del valor del control.

\section{Contaje de microorganismos en jarabes, productos de uso tópico y sólidos orales}

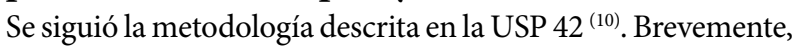
una alícuota de $1 \mathrm{~mL}$ o $1 \mathrm{~g}$ de cada muestra fue colocada en $9 \mathrm{~mL}$ de caldo TSB, en el caso de las cremas se agregó Tween 80 al 0,1\% para lograr una completa dispersión. En algunos casos se necesitaron más diluciones sucesivas para obtener un contaje adecuado de microorganismos. Las diluciones se sembraron por duplicado, tanto por extensión como por vertido, en agar soya tripticasa (TSA, por sus siglas en inglés) para el recuento total de microorganismos aerobios (RTMA) y en agar dextrosa Sabouraud (SAB, por sus siglas en inglés) para el recuento total de mohos y levaduras (RTML). Las placas de TSA se incubaron por 24 horas a $37^{\circ} \mathrm{C}$, y las de $\mathrm{SAB}$, por 5 días a $25^{\circ} \mathrm{C}$. Después de la incubación, se contaron las colonias para calcular las unidades formadoras de colonias por mililitro o gramo del producto.

\section{Detección de contaminación microbiana en los colirios}

Sobre la base de la prueba de esterilidad de la USP $42^{(10)}$ se analizaron los colirios de la siguiente manera. Todo el contenido del envase se filtró a través de una membrana de ésteres de celulosa mixta de $0,45 \mu \mathrm{m}$, este proceso se realizó en una cabina de bioseguridad Biobase A2 Clase II. Las membranas se cultivaron tanto en caldo tioglicolato como en TSB. Los dos medios se incubaron durante 14 días: el caldo tioglicolato, a $37^{\circ} \mathrm{C}$ y el de TSB, a $22,5^{\circ} \mathrm{C}$. Los tubos se examinaron diariamente y de manera visual en busca de turbidez. De los tubos positivos de tioglicolato se hicieron pases a los agares TSA, MacConkey, manitol y cetrimida y de los tubos de TSB a TSA y SAB.

\section{Identificación de microorganismos}

Los aislados bacterianos se identificaron por tinción Gram de las colonias y por su morfología en medios selectivos y diferenciales: agar manitol salado, agar MacConkey, agar cetrimida, agar XLDA y agar manitol yema de huevo. Se confirmaron los géneros y las especies de los microorganismos aislados mediante pruebas bioquímicas específicas según el tipo de microorganismo ${ }^{(11)}$.
Los hongos se identificaron mediante la observación macroscópica del crecimiento en agar SAB y por las características microscópicas en la tinción con azul de lactofenol. La identificación de Candida se hizo por tinción simple con cristal violeta, siembra en agar Candida cromogénico, prueba de tubo germinal, fermentación de azúcares y la prueba de ureasa ${ }^{(12)}$.

\section{Sensibilidad antimicrobiana}

La técnica de difusión en agar se siguió de acuerdo a los estándares del Clinical and Laboratory Standards Institute (CLSI) $2019^{(13)}$ y se evaluó la respuesta de 8 aislados de Enterobacter, 4 de Escherichia coli y uno de Klebsiella frente a diferentes antibióticos. Los antibióti$\cos$ (Bioanalyse) que se probaron fueron ertapenem $(10 \mu \mathrm{g})$, cefoxitin $(30 \mu \mathrm{g})$, cefotaxime $(30 \mu \mathrm{g})$, trimetroprim/sulfametoxazol $(1,25 / 23,75 \mu \mathrm{g})$,estreptomicina (10 $\mu \mathrm{g})$, nitrofurantoína (300 $\mu \mathrm{g})$, amoxicilina/ácido clavulánico (20/10 ug), cloranfenicol (30 $\mu \mathrm{g})$, gentamicina $(10 \mu \mathrm{g})$, azitromicina $(15 \mu \mathrm{g})$, fosfomicina $(50 \mu \mathrm{g})$, ciprofloxacina $(5 \mu \mathrm{g})$, tetraciclina $(30 \mu \mathrm{g})$, amikacina $(30 \mu \mathrm{g})$, penicilina (10 U), cefazolina (30 ug), ácido nalidíxico (30 $\mu \mathrm{g})$, piperacilina/tazobactam $(100 / 10 \mu \mathrm{g})$, imipenem (10 U), ampicilina $(10 \mu \mathrm{g})$, levofloxacina $(5 \mu \mathrm{g})$ y ceftriaxiona $(30 \mu \mathrm{g})$.

\section{Criterios microbiológicos según la USP}

Acorde a la USP $42^{(10)}$, las preparaciones orales acuosas deben tener conteos iguales o menores a $10^{2} \mathrm{ufc} / \mathrm{mL}$ para el RTMA y $10^{1} \mathrm{ufc} / \mathrm{mL}$ para el RTML; para sólidos orales, valores iguales o menores a $10^{3} \mathrm{ufc} / \mathrm{g}$ para el RTMA y $10^{2} \mathrm{ufc} / \mathrm{g}$ para el RTML. Los criterios para productos de uso tópico son los mismos que para orales acuosos. Los productos orales acuosos y no acuosos deben estar libres de Escherichia coli y los de uso tópico de Pseudomonas aeruginosa y Staphylococcus aureus. Al ser considerados productos estériles, los colirios deben estar libres de cualquier microorganismo.

\section{Análisis de los datos}

El análisis de este estudio fue descriptivo. Inicialmente se presentaron los tipos de productos naturales estudiados representando el porcentaje de cada uno de ellos frente al total de muestras. Las variables indicadoras de la cantidad de microorganismos fueron transformadas de su naturaleza cuantitativa a categorías para definir el cumplimiento del criterio microbiológico o la falta del mismo, según los valores de la USP 42. Los porcentajes de productos que no cumplen con dicho criterio fueron calculados en relación al total de productos analizados y por cada tipo de producto.

Para cada microorganismo identificado se calculó el porcentaje de productos con presencia de cada germen en relación al total de productos analizados y por cada tipo de producto. La sensibilidad/resistencia antibiótica fue catalogada de forma cualitativa sobre la base del CLSI $2019^{(13)}$. El porcentaje de cepas sensibles, con sensibilidad intermedia 
y resistentes fue calculado en relación a cada género bacteriano identificado.

\section{Aspectos éticos}

Las bases de datos manejadas en este estudio no permiten identificar información sensible como las marcas de los productos analizados, ni los sitios de su expendio.

\section{RESULTADOS}

El análisis ha sido realizado en 83 unidades de productos naturales de 38 diferentes marcas, la mayoría fueron colirios $(\mathrm{n}=30 ; 36,1 \%)$, seguido de jarabes $(\mathrm{n}=24 ; 28,9 \%)$, productos de uso tópico $(\mathrm{n}=15 ; 18,1 \%)$ y sólidos de uso oral $(\mathrm{n}=14$; $16,9 \%)$. Un total de 17 productos (20,5\%) no tenían registro sanitario ecuatoriano. En relación con el tipo de producto, en un $20,0 \%$ de los colirios, en un $36,0 \%$ de productos orales y en un $40,0 \%$ de productos tópicos no se registraba este requisito para su comercialización.

El 17,0\% de los jarabes, el 27,0\% de los productos tópicos, el $43,0 \%$ de los sólidos orales y el $80,0 \%$ de colirios no cumplen con el criterio microbiológico para el recuento total de microorganismos aerobios, mientras que aproximadamente el 33,0\% de los jarabes, 7,0\% de los productos tópicos, el $36,0 \%$ de los sólidos orales y el $20,0 \%$ de los colirios no cumplen el criterio microbiológico para mohos y levaduras (Tabla 1).

Los géneros bacterianos más frecuentemente aislados fueron Bacillus y Pseudomonas; dentro de los primeros, $B$. subtilis fue más prevalente que B. cereus. Los sólidos orales y colirios fueron los más contaminados por B. subtilis, mientras que los jarabes y los sólidos orales lo fueron por B. cereus. El 15,0\% de los productos estuvo contaminado con Pseudomonas, la mayoría de ellos fueron colirios. Otros géneros, como Staphylococcus coagulasa negativos y bacterias pertenecientes a la familia Enterobacteriaceae fueron aislados en menos del 5,0\% de las muestras y se hallaron principalmente en sólidos orales, con excepción de un solo aislamiento de Escherichia coli en una muestra de colirio. No se identificaron Staphylococcus aureus ni Salmonella spp. en ninguna de las muestras (Tabla 2).

En relación con los mohos y levaduras aislados, Aspergillus y Candida se aislaron en aproximadamente el 13,0\% de los productos. Los jarabes y los sólidos orales en el caso de Aspergillus, y los colirios, jarabes y productos tópicos en el caso de la Candida fueron los productos donde se aislaron dichos microorganismos. Penicillium fue aislado en el 5,0\% de productos, todos fueron sólidos orales. Los hongos Cladosporium y Absidia fueron aislados exclusivamente en una muestra de comprimidos cada uno (Tabla 3).

Todas las cepas aisladas de Enterobacter $(\mathrm{n}=8)$, Escherichia coli $(\mathrm{n}=4)$ y Klebsiella $(\mathrm{n}=1)$ fueron resistentes a penicilina. La única cepa aislada de Klebsiella fue resistente también a la piperacilina/tazobactam e imipenem y sensible a los demás antibióticos. De las cuatro cepas de Escherichia coli, una fue resistente a trimetroprim/sulfametoxazol, cloranfenicol, gentamicina, fosfomicina, piperacilina/tazobactam y ampicilina. De los ocho aislados de Enterobacter, siete fueron resistentes a la ampicilina, tres al cefoxitin y a la amoxicilina más ácido clavulánico, dos a la nitrofurantoína, cefazolina y piperacilina y una a la cefotaxime, trimetroprim/sulfametoxazol y ácido nalidíxico. Los tres microorganismos fueron sensibles a ertapenem, estreptomicina, ciprofloxacina, tetraciclina, azitromicina, amikacina, levofloxacina y ceftriaxona. Cinco cepas de Pseudomonas se ensayaron frente a cinco antibióticos y fueron sensibles a todos ellos: ciprofloxacina amikacina, piperacilina, imipenem y levofloxacina.

\section{DISCUSIÓN}

La calidad microbiológica de los productos analizados fue generalmente no aceptable, lo cual indica que el 46,0\% de los productos excedió los límites para el conteo de

Tabla 1. Cumplimiento de criterios microbiológicos para el recuento total de microorganismos aerobios y de mohos y levaduras en los productos naturales analizados.

\begin{tabular}{|c|c|c|c|c|}
\hline Criterio microbiológico & Jarabes & Tópicos & Sólidos Orales & Colirios $^{\star}$ \\
\hline Microorganismos aerobios & $\begin{array}{c}\leq 100 \mathrm{ufc} / \mathrm{mL} \\
\mathrm{n}(\%)\end{array}$ & $\begin{array}{c}\leq 100 \mathrm{ufc} / \mathrm{mL} \\
\mathrm{n}(\%)\end{array}$ & $\begin{array}{c}\leq 1000 \mathrm{ufc} / \mathrm{mL} \\
\mathrm{n}(\%)\end{array}$ & $\begin{array}{c}\text { Ausencia } \\
\text { n (\%) }\end{array}$ \\
\hline No & $4(16,7)$ & $4(26,7)$ & $6(42,9)$ & $24(80,0)$ \\
\hline Sí & $20(83,3)$ & $11(73,3)$ & $8(57,1)$ & $6(20,0)$ \\
\hline Mohos y levaduras & $\begin{array}{c}\leq 10 \mathrm{ufc} / \mathrm{mL} \\
\mathrm{n}(\%)\end{array}$ & $\begin{array}{c}\leq 10 \mathrm{ufc} / \mathrm{mL} \\
\mathrm{n}(\%)\end{array}$ & $\begin{array}{c}\leq 100 \mathrm{ufc} / \mathrm{mL} \\
\mathrm{n}(\%)\end{array}$ & $\begin{array}{c}\text { Ausencia } \\
\text { n (\%) }\end{array}$ \\
\hline No & $8(33,3)$ & $1(6,7)$ & $5(35,7)$ & $6(20,0)$ \\
\hline Sí & $16(66,7)$ & $14(93,3)$ & $9(64,3)$ & $24(80,0)$ \\
\hline
\end{tabular}

${ }^{\star}$ En colirios el criterio de cumplimiento es presencia o ausencia 
Tabla 2. Identificación de gérmenes bacterianos en los productos naturales analizados.

\begin{tabular}{lccccc}
\hline Microorganismo & $\begin{array}{c}\text { Total (83) } \\
\mathbf{n}(\%)\end{array}$ & $\begin{array}{c}\text { Jarabes (24) } \\
\mathbf{n}(\%)\end{array}$ & $\begin{array}{c}\text { Colirios (30) } \\
\mathbf{n}(\%)\end{array}$ & $\begin{array}{c}\text { Tópicos (15) } \\
\mathbf{n}(\%)\end{array}$ & $\begin{array}{c}\text { Sólidos Orales (14) } \\
\mathbf{n}(\%)\end{array}$ \\
\hline Staphylococcus coagulasa-negativa & $2(2,3)$ & 0 & 0 & 0 & $2(14,3)$ \\
Staphylococcus aureus & 0 & 0 & 0 & 0 & 0 \\
Escherichia coli & $3(3,5)$ & 0 & $1(3,3)$ & 0 & $2(14,3)$ \\
Enterobacter & $4(4,6)$ & 0 & 0 & 0 & $4(28,6)$ \\
Klebsiella pneumoniae & $1(1,2)$ & 0 & 0 & 0 & $1(7,1)$ \\
Salmonella & 0 & 0 & $12(40,0)$ & 0 & 0 \\
Pseudomonas & $13(15,1)$ & 0 & $6(20,0)$ & $3(20,0)$ & $5(7,1)$ \\
Bacillus cereus & $26(31,3)$ & $12(50,0)$ & $11(36,7)$ & $5(33,3)$ & $5(35,7)$ \\
Bacillus subtilis & $31(37,3)$ & $7(29,2)$ & & & $87,1)$ \\
\hline
\end{tabular}

microorganismos aerobios y el 24,0\%, para mohos y levaduras. El estudio de Saeed El-Houssieny et al. ${ }^{(14)}$ analizó también productos no estériles como jarabes, suspensiones, sólidos orales, cremas, ungüentos, lociones y geles comercializados en Egipto, y documentó que su calidad microbiológica fue adecuada, con excepción de pocos casos, como el 3,3\% de tabletas que presentaron contajes mayores a $2000 \mathrm{ufc/g}$ para bacterias y mayores a $20 \mathrm{ufc/g}$ para mohos y levaduras. El 4,2\% de los jarabes también presentó contajes aumentados en mohos y levaduras.

El genero Bacillus fue el más predominante en nuestro estudio, estas bacterias suelen ser frecuentes en los ambientes de producción farmacéutica y en la materia prima, debido a su capacidad de formar endosporas y resistir condiciones de resequedad y falta de nutrientes. Su presencia se ha reportado frecuentemente ${ }^{(15,16)}$ y podría indicar una falta de control ambiental en el sitio de fabricación, acondicionamiento, almacenamiento o distribución. El 20,0\% de colirios estuvo contaminado por Bacillus cereus, y el $37,0 \%$ por Bacillus subtilis, estos microorganismos podrían causar serias infecciones a nivel ocular. Un estudio en el Cairo-Egipto ${ }^{(17)}$ también analizó gotas oculares y de las 58 muestras positivas para la presencia de microorganismos, el 55,1\% estuvieron contaminadas con Bacillus spp.

Un hallazgo relacionado con prácticas de higiene deficientes en la elaboración de productos fue el descubrimiento de entero- bacterias, entre ellas, Escherichia coli, presente en el 3,3\% de los colirios y en el 14,3\% de los sólidos orales. Escherichia coli es un bacilo Gram negativo propio de la flora intestinal de mamíferos y otros animales, su presencia en agua, alimentos y productos farmacéuticos es un fuerte indicativo de contaminación fecal. Obi et al. ${ }^{(18)}$ analizaron tabletas (naturales y sintéticas) de venta en Nigeria y determinaron también la presencia de Escherichia coli en todos los productos colectados en farmacias, hospitales y tiendas naturistas de Abia State.

La contaminación de la materia prima con enterobacterias también es posible, Ratajczak et al. ${ }^{(19)}$ analizaron la calidad microbiológica de productos farmacéuticos no estériles, y en aquellos que contenían materias primas de origen natural se aisló Escherichia coli. Los hallazgos se atribuyeron a la falta de un tratamiento previo para disminuir la carga microbiana de la materia prima, así como a una deficiente calidad del agua y el suelo de cultivo.

Otras enterobacterias aisladas en los sólidos orales de nuestro estudio fueron Klebsiella y Enterobacter, lo que apoya el hecho de un posible tratamiento inadecuado de la materia prima, así como deficientes prácticas agrícolas, pues la contaminación fecal del suelo y los cultivos puede deberse al uso de fertilizantes naturales a base de heces de animales, donde las enterobacterias son los principales microorganismos. Ninguno de los productos analizados estuvo contaminado por Salmonella, lo que concuerda con lo reportado por Shaqra et al. ${ }^{(15)}$, pero difiere

Tabla 3. Identificación de mohos y levaduras en los productos naturales analizados.

\begin{tabular}{lccccc}
\hline Microorganismo & $\begin{array}{c}\text { Total (83) } \\
\mathbf{n}(\%)\end{array}$ & $\begin{array}{c}\text { Jarabes (24) } \\
\mathbf{n}(\%)\end{array}$ & $\begin{array}{c}\text { Colirios (30) } \\
\mathbf{n}(\%)\end{array}$ & $\begin{array}{c}\text { Tópicos (15) } \\
\mathbf{n}(\%)\end{array}$ & $\begin{array}{c}\text { Sólidos orales (14) } \\
\mathbf{n}(\%)\end{array}$ \\
\hline Aspergillus & $11(13,2)$ & $7(29,2)$ & 0 & 0 & $4(28,6)$ \\
Candida & $11(13,2)$ & $4(16,7)$ & $6(20,0)$ & $1(6,7)$ & 0 \\
Cladosporium & $1(1,2)$ & 0 & 0 & 0 & $1(7,1)$ \\
Absidia & $1(1,2)$ & 0 & 0 & 0 & $1(7,1)$ \\
Penicillium & $4(4,8)$ & 0 & 0 & 0 & $4(28,6)$ \\
\hline
\end{tabular}


de los hallazgos de Rauf et al. ${ }^{(20)}$ que reportan este patógeno en suspensiones, jarabes y tabletas en su estudio realizado en preparaciones no estériles en Paquistán.

Pseudomonas, una bacteria potencialmente patógena causante de queratitis resistente a múltiples antibióticos ${ }^{(21)}$, se encontró en el 40,0\% de los colirios, productos que según la USP deben ser estériles. Este microorganismo tiende a formar biofilms, y su presencia puede deberse a sistemas inapropiados de distribución y almacenamiento del agua purificada para uso farmacéutico ${ }^{(22)}$.

Aspergillus y Penicillium fueron los géneros de mohos más frecuentemente aislados, lo que podría indicar un control poco adecuado de las condiciones ambientales, niveles inapropiados de humedad y temperatura. Estos microorganismos, además de deteriorar los productos, podrían afectar la salud de los usuarios, en especial aquellos con un sistema inmune debilitado, debido a que pueden producir toxinas como resultado de su metabolismo ${ }^{(23)}$.

Levaduras como Candida se aislaron en $16,7 \%$ de los jarabes, en $20,0 \%$ de los colirios y en 7,0\% de los tópicos. Su hallazgo puede deberse a un manejo inadecuado de buenas prácticas higiénicas por parte de los operadores, ya que este microorganismo es miembro de la microbiota intestinal y urogenital. El aislamiento de Candida podría considerarse un problema de salud pública, debido a que es uno de los principales causantes de infecciones asociadas en pacientes con VIH y se han detectado cepas resistentes a antibióticos como el fluconazol $^{(24)}$.

En las muestras del presente estudio, no se aisló Staphylococcus aureus, lo que contrasta con lo encontrado por Stanley et al. ${ }^{(25)}$ en Nigeria, quienes analizaron productos naturales sólidos y líquidos, y Staphylococcus aureus fue la bacteria más prevalente, lo que podría indicar una manipulación incorrecta de los productos por el personal.

En cuanto a la respuesta de los bacilos Gram negativos, como Enterobacter y Escherichia coli, a diferentes antibióticos, se observó que los productos analizados pueden ser fuente de bacterias farmacorresistentes. En el estudio de Daniyan y Sangodere ${ }^{(26)}$, donde evaluaron jarabes en Minna Metrópolis en Nigeria, se analizó el patrón de susceptibilidad antimicrobiana de Escherichia coli, Staphylococcus aureus y Bacillus subtilis, y se encontró que también exhibían una amplia resistencia a los antibióticos.

El tipo y la cantidad de contaminación microbiana encontradas en este estudio son un fuerte indicativo de una deficiente aplicación de BPM, escaso control del ambiente de fabricación, pobre calidad de la materia prima y del agua empleada, así como una inadecuada higiene del personal a cargo de los procesos. De manera que es obligatorio que los establecimientos donde se fabrican, almacenan, distribuyen y comercializan productos naturales procesados de uso medicinal cumplan con la implementación de BPM, de lo contrario, la salud de los usuarios puede estar en peligro. Las BPM para productos naturales en países y regiones del primer mundo, como China y la Unión Europea, y en menor medida los Es- tados Unidos, toman como eje la evaluación y la gestión del riesgo, más que el aseguramiento y control de la calidad que, de manera desfasada, aún es recomendada por la OMS ${ }^{(27)}$. En el Ecuador debería privilegiarse el primer enfoque, puesto que no solo considera la multiplicidad de factores que están involucrados en la calidad de los medicamentos, sino que permite racionalizar y concentrar los usualmente escasos recursos en los aspectos de mayor impacto para su seguridad y eficacia.

Entre las limitaciones de este estudio, debemos considerar que los resultados obtenidos son exclusivamente aplicables a los productos y marcas analizadas, puesto que otros productos naturales podrían variar en origen y manufactura. Debido a que la selección de las muestras no fue aleatoria, es difícil generalizar los resultados a otros productos naturales. De igual forma, desconocemos si los productos estudiados realmente contienen ingredientes naturales, sin embargo, independientemente del origen, nuestros resultados muestran el déficit en la calidad microbiológica de estos productos de libre venta en la ciudad.

Las fortalezas de nuestro análisis radican en investigar una variedad de formas farmacéuticas para diferentes rutas de administración y de diversa composición y características fisicoquímicas, que abarcan líquidos, semisólidos y sólidos, estériles y no estériles, nacionales e importados, lo cual representa un panorama general de la calidad microbiológica de los productos comercializados en Quito. Igualmente, los métodos de conteo e identificación que se aplicaron en este estudio constan en la bibliografía oficial (USP).

En conclusión, este análisis microbiológico de productos naturales procesados de uso medicinal demuestra que el $46,0 \%$ de estos presenta niveles no aceptables en el conteo de microorganismos aerobios, y el $24,0 \%$, en el de mohos y levaduras. Se aislaron microorganismos indicadores de un deficiente control del ambiente de fabricación o almacenamiento, de prácticas de higiene deficientes, especialmente en sólidos orales, y también se aislaron bacterias potencialmente patógenas y farmacorresistentes. Estos hallazgos implican que los productos podrían no ser aptos para su distribución y consumo, aun cuando muchos de ellos cuenten con registro sanitario. Su control y regulación son indispensables y la aplicación de normativas por los entes regulatorios debe ser impostergable.

Agradecimientos: Agradecemos a la Universidad Central del Ecuador por la creación de programas de investigación formativa para alumnos y docentes. A la Dra. Luz María Martínez por sus valiosos comentarios sobre el manuscrito.

Contribuciones de los autores: DC, RE, GA, JM, JSA, FZ y RT concibieron y diseñaron el estudio; DC, RE, GA, JM y FZ recopilaron datos; PE y RT procesaron, analizaron e interpretaron los datos; PE, JSA, DC y RT redactaron el artículo. Todos los autores aprobaron la versión final.

Fuentes de financiamiento: Este proyecto fue en su mayor parte autofinanciado por los autores y en parte por los fondos para «Proyectos Semilla» fase 3 de la Universidad Central del Ecuador.

Conflicto de intereses: Los autores declaran no tener conflicto de interés. 


\section{REFERENCIAS BIBLIOGRÁFICAS}

1. Kosalec I, Cvek J, Tomić S. Contaminants of Medicinal Herbs and Herbal Products. Arch Ind Hyg Toxicol [Internet]. 2009 [citado 13 de febrero de 2019]; 60(4):485-501. Disponible en: http://content.sciendo.com/view/ journals/aiht/60/4/article-p485.xml.

2. World Health Organization. WHO guidelines on good manufacturing practices (GMP) for herbal medicines. 2007 [citado 28 de abril de 2020]; Disponible en: https://apps.who.int/iris/handle/10665/43672.

3. Okunlola A, Adewoyin BA, Odeku OA. Evaluation of Pharmaceutical and Microbial Qualities of Some Herbal Medicinal Products in South Western Nigeria. Trop J Pharm Res. 2007;6(1):661-70.

4. Enayatifard R, Asgarirad H, Kazemi-Sani B. Microbial quality of some herbal solid dosage forms. African J Biotechnol. 2010;9(11):1701-5.

5. Braide W, Oranusi SU, Nwaoguikpe RN, Chike-reginald CIAC, Popgbara LB. Evaluation of the Microbiological Status and Antibacterial Susceptibility Pattern of Some Herbal Remedies Administered Orally in Nigeria. Research Journal in Engineering and Applied Sciences. 2013;2(1):35-42.

6. Food and Drug Administration. Pharmaceutical Quality Resources [Internet]. FDA. 2020 [citado 25 de abril de 2020]. Disponible en: https:// www.fda.gov/drugs/development-approval-process-drugs/pharmaceutical-quality-resources.

7. Freitas Araujo MG de, Maria T. Microbial Quality of Medicinal Plant Materials. En: Latest Research into Quality Control [Internet]. InTech; 2012 [citado 20 de abril de 2020]. Disponible en: http://www.intechopen. $\mathrm{com} /$ books/latest-research-into-quality-control/microbial-quality-of-medicinal-plant-materials.

8. Suplemento - Registro Oficial No. 891. Normativa técnica sanitaria sustitutiva para la obtención del Registro Sanitario y control de productos naturales procesados de uso medicinal y de los establecimientos en donde se fabrican, almacenan, distribuyen y comercializan [Internet]. Registro oficial. Órgano de la República del Ecuador. 28 de noviembre de 2016 [citado 13 de junio de 2019] Disponible en: https://www.registroficial.gob.ec/index.php/registro-oficial-web/publicaciones/suplementos/ item/8625-suplemento-al-registro-oficial-no-891.

9. Control Sanitario. Normativa Sanitaria Para La Obtención Del Registro Sanitario,2016 [Internet]. Quito: Agencia Nacional de Regulación, Control y Vigilancia Sanitaria; 2016 [citado 12 de agosto de 2019]. Disponible en: https://www.controlsanitario.gob.ec/wp-content/uploads/downloads/2016/12/ARCSA-DE-023-2016-YMIH_NORMATIVA-TECNICA-SANITARIA-SUSTITUTIVA-PARA-LA-OBTENCION-DEL-2.pdf.

10. The United States Pharmacopeial Convention. The United States Pharmacopeia. National Formulary. Vol. 4. En: United States Pharmacopeia USP 42. Rockville (MD); 2019. p. 6462-76.

11. Cundell AM. Microbial identification strategies in the pharmaceutical industry. PDA J Pharm Sci Technol. 2006;60(2):111-23.

12. Vijayakumar R, Sandle T, Manoharan C. A review on fungal contamination in pharmaceutical products and phenotypicidentification of contaminants by conventional methods. Eur J Parenter Pharm Sci. 2012;17(1):4-18.

13. CLSI. Performance Standards for Antimicrobial Susceptibility Testing.
CLSI Supplement M100. 29 $9^{\text {th }}$ ed. Wayne, PA: Clinical and Laboratory Standards Institute; 2019. 1-282 p.

14. El-Houssieny RS, Aboulwafa MM, Elkhatib WF, Hassouna NAH. Recovery and detection of microbial contaminants in some non-sterile pharmaceutical products. Arch Clin Microbiol. 2013;4(6):1-14.

15. Shaqra Q, Shawaqfah M, Al Momani W. Microbiological Quality of Blister Pack Tablets in Community Pharmacies in Jordan. Trop J Pharm Res. 2014;13(2):261.

16. Agbo BE, Takon IA, Ajaba MO. Prevalence of Contaminating Microorganisms in Anti-Malarial Drugs Sold in Calabar, Cross River State, Nigeria. Int J Pharm Sci Res. 2016;7(10):4272-7.

17. Abo-State MAM, Husseiny SHM, Helimish FA, Zickry ARA. Contamination of Eye Drops with Bacillus Species and Evaluation of Their Virulence Factors. World Appl Sci J. 2012;19(6):847-55.

18. Obi CN, Nwannunu U. Microbiological analyses of drug tablets from selected outlets in Umuahia, Abia State, Nigeria. Res J Pharmacol. 2010;4(2):31-7.

19. Ratajczak M, Kubicka MM, Kamińska D, Sawicka P, Długaszewska J. Microbiological quality of non-sterile pharmaceutical products. Saudi Pharm J. 2015;23(3):303-7.

20. Rauf A, Erum A, Noreen S, Shujaat J, Ashraf MU, Afreen S. Microbiological quality control of some non-sterile preparations commonly used in Pakistan. Pak J Pharm Sci. 2018;31(4):1237-42.

21. Vazirani J, Wurity S, Ali MH. Multidrug-resistant Pseudomonas aeruginosa keratitis: Risk factors, clinical characteristics, and outcomes. Ophthalmology. 2015;122(10):2110-4.

22. MaX, Zhang G, Li G, Wan Y, Sun H, Wang H, et al. Biofilm bacterial community transition under water supply quality changes in drinking water distribution systems. Environ Sci Water Res Technol. 2018;4(5):644-53.

23. Gad G, Aly R, Ashour M. Microbial Evaluation of Some Non-sterile Pharmaceutical Preparations Commonly Used in the Egyptian Market. Trop J Pharm Res. 2011;10(4):437-45.

24. De Paula SB, Morey AT, Santos JP, Dos Santos PMC, Gameiro DG, Kerbauy G, et al. Oral Candida colonization in HIV-infected patients in Londrina-PR, Brazil: antifungal susceptibility and virulence factors. J Infect Dev Ctries. 2015;9(12):1350-9. Disponible en: https://jidc.org/ index.php/journal/article/view/26719941.

25. Stanley C, Ibezim C, Diorgu F. Evaluation of the Claims of Microbiological Activity and Microbiological Quality ofSome Oral Herbal Medicinal Products Sold in Port-Harcourt Metropolis. Microbiol Res J Int. 2018;23(6):1-16.

26. Daniyan SY, Sangodere TA. Microbial Assessment of Some Syrup Sold in Patent Medicine Stores in Minna Metropolis, Nigeria. Int Res J Pharm. 2011;2(8):58-61.

27. He T-T, Ung COL, Hu H, Wang Y-T. Good manufacturing practice (GMP) regulation of herbal medicine in comparative research: China GMP, cGMP, WHO-GMP, PIC/S and EU-GMP. Eur J Integr Med. 2015;7(1):55-66. 